\title{
Mobile Technologies Enhance The E-Learning Opportunity
}

\author{
Keh-Wen "Carin” Chuang, Purdue University North Central, USA
}

\begin{abstract}
The objective of this paper is to identify the mobile technologies that enhance the E-Learning opportunity, examine the educational benefits and implementation issues in mobile learning, discuss the guidelines for implementing effective mobile learning, identify the current application and operation of mobile learning, and discuss the future of teaching and learning with mobile technologies.
\end{abstract}

Keywords: mobile technologies, educational benefits, teaching and learning, E-learning.

\section{INTRODUCTION}

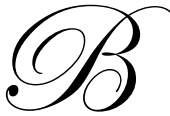

ased on an academic study published at "AcademicDB.com", online learning started over 30 years ago with the use of Teletype terminals linked to mini and mainframe computers, which evolved into PCs and then followed by multimedia. The technology in the 1970s which is now used to deliver online training began with the development of computer-based training (CBT). Due to further advances in computer and telecommunication technologies in 1990s, new forms of distance learning were introduced, for example, Internet and Web-based classes and computer-based training on CD ROM. The Internet was made widely available to the general public, companies and large corporations in the middle 1990s. In its infancy, text only training was available which took the form of bulletin boards, software downloading and e-mails. Then, due to further advances in technology, graphical browsers were introduced, these employed a single program, which performed all of the above functions and made communication very user friendly and efficient.

E-Learning can be defined as the delivery of learning or education programs via all electronic media, including the Internet, intranets, satellite broadcast, audio/video tapes, interactive TV, and CD-ROM (Learn Frame, 2008). It is used synonymously with technology-based learning. E-Learning can involve a greater variety of equipment than online training or education. It can be synchronous, i.e. Real-time chat, video/audio conferencing, web-based or computer conferencing. Asynchronous, i.e., involving self paced courses, exchange of email messages with mentors, or use of electronic performance system discussion groups. There are two types of learning available via the Internet E Learning and Online Learning. E learning or distance learning, which refers to training or education delivered via the Internet instead of the usual classroom, book, video or CD ROM. This is also referred to "Web based training (WBT)". Web based training is defined as teaching or instruction which is delivered by a web browser via the Internet or a corporate intranet (Learn Frame, 2008). There are four basic methods of WBT.

In the past decade, the world is going mobile. Phones, computers and media devices now fit in our pockets and can connect us to a variety of information sources and enable communication nearly everywhere we go. In recent years, universities have made significant investments in technology systems to support various aspects of students' studies and learning. These include the infrastructure and course management systems, all of the work is to attract or "pull" students into the online environment of the university. (Armatas, Holt, \& Rice, 2005) On the other hand, students have come increasingly equipped with newer mobile devices which "push" information to students allowing quick and easy communication and information sharing, so that each adds value to and complements the other. This paper will identify the mobile technologies that enhance the E-Learning opportunity, examine the educational benefits and implementation issues in mobile learning, discuss the guidelines for implementing effective mobile learning, identify the current application and operation of mobile learning, and discuss the future of teaching and learning with mobile technologies. 


\section{MOBILE LEARNING VS. E-LEARNING}

E-Learning is the learning that involves interaction between learners and computers. It may incorporate text, graphics, narration, sound effects, music, video, and animation to enhance the learning experience. To this extent, how will learning on mobile devices be very different from the e-learning with desktop computers and laptops?

There are several issues related to the use of mobile devices that make them very different compared to desktop and even laptop computers. From a teaching and learning standpoint, these differences are very significant.

First, the general mobile devices are almost always with the learners. Nowadays, research shows that there are three things people almost always carry with them: keys, a wallet, and mobile devices. Mobile devices include cellular phone, PDA and MP3 player. General speaking, people want to carry mobile devices with them because they want to be reachable. Since the mobile device is so easily accessible makes it a great tool for note taking or problem solving. Learners can simply make a phone call or text their instructors or friends to get their opinion or advice. The easy access makes a mobile device also a great tool to help learning occur at anywhere and anytime. Learners may play gaming simulation and other interactive applications, listen to podcasts, watch videos, read the news or even join discussion. When learners start to think and guide their learning the mobile learning model becomes much more efficient. Learners may read an e-book or listen to a podcast with an aim to learn something from it. This kind of informal learning can take place outside the traditional learning environment. Mobile phones are very useful tools for informal learning. Learning materials that are delivered on mobile devices may reach many people that can be hard to reach with any other media. For instance, instructors may offer educational mobile games, podcasts or video clips for their target groups.

Second, using mobile devices is not limited to informal learning. Several schools and universities are already using mobile devices to manage learning related tasks, such as calendars, reminders, announcements, registration, and school-home communication.

Third, mobile devices are by nature social devices, especially the cellular phones. As such they are potential tools for enhancing a cooperative learning environment. They are everyday tools that can help students exchange information and for creating and maintaining their social networks.

\section{MOBILE TECHNOLOGY INTEGRATION}

There are many different types of technology that can be classified as 'mobile technology' as they have the 'portable' and 'movable' features and also implicate a 'personal' as opposed to 'shared' context of use (Naismith et al, 2004). Therefore, we can classify the range of mobile technologies using the two dimensions of personal vs. shared, and portable vs. static. The first type of device can be classified as both portable and personal. This type of device is what people most commonly think of in relation to mobile technologies; such as mobile phones, personal digital assistants (PDAs), MP3 players, tablet PCs and laptops. Since these devices normally support a single user, they are generally perceived as being personal. This type of mobile device affords communication and information sharing, which means that while the devices themselves are personal, the information within them can be shared easily. These devices are portable as they are taken from place to place, so they can be available in many different locations.

The second type of mobile technologies is less portable, but still can offer personal interactions with learning experiences. Classroom response systems consist of individual student devices that are used to respond to multiple choice questions administered by teachers. This technology is static that it can only be used in one location, but remains personal because of its small size and allocation to one single user.

The third type of examples is technologies that can provide learning experiences to users on the move, but the devices are not physically movable. Street kiosks, or interactive museum displays offer pervasive access to information and learning experiences, but it is the learner who is portable, not the delivery device. This type of mobile device is less personal and is likely to be shared between multiple users. 
The fourth type of mobile technology is the device with more shareable interactions but less portable. Examples include interactive classroom whiteboards and video-conferencing facilities. However, according to Naismith et al, this type of technology would generally not be classified as mobile technologies. The scope of this paper focus is on the first type of mobile device, as this type of mobile devices is the most commonly utilized by students in mobile learning.

\section{MOBILE LEARNING}

Mobile learning (or m-learning) means learning that is enhanced with mobile tools and mobile communication. Many people see it as a follow-up to e-learning, where the computers and Internet are used for teaching and learning. One definition of mobile learning is: Learning that happens across locations, or that takes advantage of learning opportunities offered by portable technologies. The feature of the mobile learning is selfpaced, on-demand, and real-time instruction that can be accessed by students from almost anywhere. Due to the high level of mobile phone penetration, the mobile phone devices are ideal targets for mobile learning applications. Presently, students make use of their mobile phones educationally to contact faculty, staff and fellow students. This is most usually accomplished via voice. Students also use the non-voice service, such as using short message service (SMS) to text other students, or transferring data (e.g., sending pictures, video files, web browsing, etc.). In addition, the educational benefits that could be created through using mobile technologies to enhance students' learning experience include (Armatas et al, 2005):

- $\quad$ Deliver multimedia materials designed specifically for mobile devices

- $\quad$ Deliver interactive tasks, e.g., online quizzes

- $\quad$ Add value and incentive to attend and actively participate in lectures

- $\quad$ Allow students to browse what is available in the online environment

- $\quad$ Break communication bottlenecks by communicating directly with students

- Encourage students to discover principles for themselves. In order to transform learners from passive recipients of information to active constructors of knowledge. Within the mobile learning framework, the instructors give the students an environment in which to participate in the learning process, and the tools to work with that knowledge.

However, there are some issues as well in implementing mobile learning:

- $\quad$ Problem of localized content: some questions were not relevant to what a particular student had studied.

- $\quad$ Lack of detailed feedback for learners: the small screen size and memory capacity of the mobile devices mean that no detailed feedback about question responses could be given.

- Compatibility across devices: despite Java being promoted as a cross-platform environment, it is still difficult to get the Java game running on all mobile phones.

- $\quad$ Costs: the text service is still an additional charge on almost all mobile phones, which would lead to a significant decline in popularity and thus cause issues in implementation.

\section{GUIDELINES FOR MOBILE LEARNING IMPLEMENTATION}

Teaching and learning with mobile technologies is beginning to make a breakthrough from small-scale pilots to large institutional implementations. The following guidelines were developed to describe effective implementation in mobile learning, and may also be useful to inform policy initiatives (Wagner, 2005):

1. Investigate a cost model for the infrastructure, technology and services. Various costs should be considered when implementing mobile learning. In addition to the significant initial capital expenditure required to purchase devices and networking equipment, there is the ongoing cost of technical support and also various 'hidden' costs.

2. Study the requirements of all those involved in the use of the technology (learners, teachers, content creators) to ensure that it is usable and acceptable. The usability should account for both the users that will 
be creating the mobile content and those who will be using the mobile applications to learn from or teach with.

3. Assess that the technology is suited to the learning task and examine the advantages and disadvantages of each technology before making a decision on which one to use. The effective implementation of mobile learning requires a clear pedagogical approach, identification of specific learning needs/goals and teachers to be directly involved in decisions on planning and curriculum use.

4. Assign the necessary roles for initiating and thereafter supporting mobile learning. For example, hire or assign a technical promoter who will demonstrate the capabilities of the system. Once mobile technologies are in place, institutions can also benefit from technical experts to deal with equipment failures and ongoing system improvements.

5. Develop procedures and strategies for the management of equipment when it is provided by the institution.

6. Provide training and ongoing technical support to the teachers to enable them to use mobile technologies to enhance current activities and to enable new instructional activities.

7. Consider the use of mobile technologies for student administration tasks. Mobile devices can be used to maintain accurate lists of classes which can be used in conjunction with rich information about students to help draw out individual students needs.

8. Consider the use of mobile technologies to support collaborative and group learning.

9. Discover and adopt suitable applications that match the needs of your specific classroom and map directly to your curriculum needs.

10. Ensure security and privacy for the end users. Privacy protection includes both the student's personal data and the student's current location.

\section{CASE IMPLICATION}

The mobile learning operated at Purdue University North Central (PNC) is in the MBA program. The MBA program at PNC currently made use of Adobe Connect for one of their courses, MGMT650, Strategic Management. This course was taught face-to-face to on-campus students while simultaneously being delivered to a student at a distance. Adobe Connect is a recordable web meeting room for live online meetings, lectures, and presentations. Adobe Connect offered a solution to the problem of how to deliver instruction to a single distance education student. Use Connect for real-time instructional delivery or for meetings and seminars enriched with interactive presentations and discussion capabilities. Instructors can combine existing learning content with realtime interactivity between presenters and students for engaging collaborative teaching and learning experiences. Presenters can use PowerPoint slides, live and recorded video, Flash animations, live screen-sharing, audio and twoway text chat to deliver a more effective learning experience.

\section{CONCLUSIONS}

The mobile technologies have provided the means and the methods for demonstrating that learning no longer need to be classroom bounded. The capabilities of mobile devices will likely merge even more to provide a networked, multimedia device that is always with you. The integrated capabilities will transform everyday activities by providing the ability to capture details about the time, location, and people around you. The entire Internet will become both personal and portable (Wagner, 2005).

Learning can happen any time and everywhere. Most of our learning takes place in informal situations where we do not even think we are learning. We simply adapt to the environment and social situations we are living in. Mobile leaning enhances this opportunity for informal learning.

The challenges for the educators and technology developers of the future will be to find ways to ensure that this new learning is highly situated, personal, collaborative and long term; which means a truly learner-centered learning experience (Siff, 2006). Educators will need to adapt from a role as transmitters of knowledge to guiders of learning resources. Technology developers will need to respond to concerns of security and privacy while designing devices and services that learners both want and will pay for. 
Whether we like it or not, the mobile devices are finding their way into classrooms and in students' pockets. We must ensure that educational practice can include these technologies in productive ways. In the future, the success of learning and teaching with mobile technologies will be measured by how seamlessly it weaves itself into our daily lives, where we don't even recognize it as learning at all.

\section{AUTHOR INFORMATION}

Keh-Wen (Carin) Chuang, MS. is an assistant professor in the Department of Computer \& Information Technology at Purdue University North Central. Before entering academia, Professor Chuang has been spent over 12 years of professional experience in database administration and information system development for three Fortune 100 companies in Illinois, Indiana and Michigan. Professor Chuang is a certified JAVA developer, SQL Server Administrator and E-Commerce Web Site Developer.

Professor Chuang earned her two Master degrees in Information Systems and Urban Studies at Michigan State University, and her BBA in International Economics from Soochow University at Taiwan.

\section{REFERENCES}

1. Adjusting to the New Opportunities Within Learning, Retrieved May 31, 2005, from: http://www.academicdb.com/library?d=1;page=record;link=4083

2. Armatas, C., Holt. D., \& Rice. M., Balancing the Possibilities for Mobile Technologies in Higher Education, Ascilite 2005: Balance, Fidelity, Mobility: Maintaining the Momnentum? 27-35.

3. Auburn School District, What is a Server? School district website [Online], Retrieved May 31,2005, from: http://www.auburn.wednet.edu/Info/What_is_a_server.htm

4. Evaluation of British Petroleum's Learning Effectiveness, Retrieved May 31, 2005, from: http://www.academicdb.com/library?d=1;page=record;link=14544

5. Learning Styles, Retrieved May 30, 2005, from: http://www.xu.edu/lac/learning styles.htm

6. Naismith, L., Lonsdale, P., Vavoula, G., \& Sharples, M., Literature Review in Mobile Technologies and Learning, Futurelab Series, Report 11, 2004.

7. O’Brien, J. A., \& Marakas, G. M., Management Information Systems, New York, NY: McGraw-Hill Irwin, 2006.

8. Siff, F. H., Mobility and Higher Education: Not Just the Next Big Thing, Educause Center for Applied Research, Research Bulletin, Vol 2006, Issue 22.

9. Successful Online Student, Retrieved June 5, 2005, from: http://www.ion.uillinois.edu/resources/tutorials/pedagogy/StudentProfile.asp

10. Teaching Styles, Retrieved June 4, 2005, from: http://members.shaw.ca/mdde615/tchstycats.htm

11. The History of Online and E-learning, Retrieved May 31, 2005, from: http://www.academicdb.com/library?d=1;page=record;link=4153

12. The future of e-learning, Retrieved May 31, 2005, from: http://www.corollis.com/article future.htm

13. The Impact of Computers on Education, Retrieved May 31, 2005, from: http://www.academicdb.com/search.cgi?query=The+Impact+of+Computers+on+Education

14. Wagner, E. D., Enabling Mobile Learning, Educause Review, Vol 36, No. 3, May/June 2005. 
NOTES 